\title{
Civic Writing on Digital Walls
}

Manuscript accepted for publication in Journal of Literacy Research.

Correspondence concerning this manuscript should be addressed to:

\author{
Jeremiah H. Kalir \\ University of Colorado Denver \\ School of Education and Human Development \\ 1380 Lawrence St., Suite 645 \\ Denver, CO 80204 \\ (303) 315-0034 \\ remi.kalir@ucdenver.edu \\ Antero Garcia \\ Stanford University \\ Graduate School of Education \\ 520 Galvez Mall \\ Stanford, CA 94305 \\ (310) $739-1885$ \\ antero.garcia@stanford.edu
}

\begin{abstract}
Civic writing has appeared on walls over centuries, across cultures, and in response to political concerns. This article advances a civic interrogation of how civic writing is publicly authored, read, and discussed as openly accessible and multimodal texts on digital walls. Drawing upon critical literacy perspectives, we examine how a repertoire of ten civic writing practices associated with open web annotation (OWA) helped educators develop critical civic literacy. We introduce a social design experiment in which educators leveraged OWA to discuss educational equity across sociopolitical texts and contexts. We then describe a single case of OWA conversation among educators and use discourse analysis to examine shifting situated meanings and political expressions present in educators' civic writing practices. We conclude by considering implications for theorizing the marginality of critical civic literacy, designing learning environments that foster educators' civic writing, and facilitating learning opportunities that encourage educators' civic writing across digital walls.
\end{abstract}

\section{Keywords}

Digital literacy, Formative design experiment, Discourse/discourse analysis, Technology, Critical literacies 


\section{Introduction}

Civic writing has appeared on walls over centuries, across cultures, and in response to varied political concerns. Martin Luther hammered his Ninety-five Theses to the door of All Saints' Church in 1517. Wei Jingsheng displayed The Fifth Modernization on Beijing's

Democracy Wall in 1978. These examples reverberate in contemporary civic writing, as with the artist Alexandra Bell whose public posters reimagine New York Times articles by "deploying marginalia, obscuring whole passages with fat black ink, and rewriting headlines, captions, and other text" (Neason, 2017, par. 2) thereby challenging the publication's use of racial stereotypes. Such civic writing is produced by a range of everyday media--ink, text, hypertext--and both appears atop and is circulated among information environments as dissent, expression, and an invitation for dialogue. The amplification of \#MeToo in 2017 included the poet Isobel O’Hare utilizing the erasure genre to transform sexual misconduct apology statements into blackout poems posted to and shared across the "walls" of social media platforms (O'Hare, 2018). Whether etched into the built environment (Mattern, 2017) or woven within a digital landscape (Tufekci, 2017), multimodal civic writing emerges from civic dialogue among peers and, subsequently, inspires conversation about civic participation.

We advance a "civic interrogation" (Mirra \& Garcia, 2017), defined as a critical analysis of normative civic practices that, in this article, questions how educators author civic writing, how such writing is composed, and why such writing matters. Specifically, we interrogate how civic writing by $\mathrm{K} 12$ and post-secondary educators is publicly authored, read, and discussed as openly accessible across the "walls" of a digital environment. Our study of educators' civic writing on digital walls emerges amidst broader--and changing--literacies practiced by both youth and educators that thrive inside and outside of school (Lizárraga \& Gutiérrez, 2018; 
Serafini \& Gee, 2017). We recognize that expansive definitions of text and literacy (Lankshear \& Knobel, 2011; New London Group, 1996) and the participatory production of multimedia (Jenkins, 2006; Jenkins, Ito, \& boyd, 2015), have influenced novel conceptions of civic literacy (Mirra, Morrell, Cain, Scorza, \& Ford, 2013; Morrell, 2013).

Emergent forms of civic writing have changed what counts as civic literacy (Garcia et al., 2015), including how writers--of all ages--exercise political agency, contribute to social movements, and advocate change (Taylor, 2014). From digital writing within online affinity spaces (Jenkins et al., 2015) to the previously mentioned plaster posters of Alexandra Bell, civic writing speaks to particular audiences for both local and wide-ranging purposes. Deliberate civic writing practices galvanize specific communities to remark upon issues germane to their social fabric and political concerns (Jenkins, 2006). These qualities of civic writing echo Barthes' (1977) view of textual landscapes as sites for political learning, engagement, and conflict. A challenge for authors, readers, and texts, according to Barthes, is the realization that "a text is not a line of words releasing a single 'theological' meaning (the 'message' of the Author-God) but a multi-dimensional space in which a variety of writings, none of them original, blend and clash" (p. 146). We seek to identify how educators' writing on digital walls amplifies the blending and clashing of personal, political, and pedagogical expression and, therefore, may be analyzed as civic writing. Educators, we will argue, can author new and distinctive forms of civic writing across everyday texts, contexts, and digital spaces.

Our study focuses on how a repertoire of social and technical practices associated with open web annotation (OWA) supported educators' civic writing on digital walls. We define OWA as digital annotation practices that embrace open web standards, advocate open principles, and nurture open practices online (Kalir, 2018). While not all OWA is civic writing (e.g., Chen, 
2018), OWA can encourage opportunities for civic writing, just as civic writing can encourage the development of civic literacy. In this study, we approach educators' use of OWA for public civic writing from a critical theoretical perspective which suggests that, under certain conditions, OWA can foster critical and digital civic literacy. Following a review of this study's theoretical perspective, we introduce social design experiment methodology (Gutiérrez \& Jurow, 2016) to contextualize educators using OWA to discuss educational equity across sociopolitical texts and contexts (Kalir \& Perez, 2019). Next, we present a single case of an OWA conversation among educators about civic imagination and innovation. We use discourse analysis methods to identify a heuristic that describes ten civic writing practices demonstrated by educators. We conclude with theoretical, design, and implementation recommendations useful for literacy researchers and educators interested in using OWA to inspire civic writing and promote civic literacy.

\section{Theoretical Perspectives}

\section{Critical and Civic Literacy}

This study is built upon a critical foundation that highlights power, identity, and reflexivity in literacy practices. In particular, we embrace Freire and Macedo’s (1987) explanation that learning to read the word is an activity preceded by first reading the world. This sociocultural framing recognizes how individuals' identities, cultures, and various communities shape the meaning of literacy practices--and how those practices are interrupted and enacted. Power and authority are substantive aspects of this critical perspective that acknowledges how the cultural dimensions of meaning are ascribed to texts and their production. As such, we work within a scholarly and pedagogical tradition that "melds social, political, and cultural debate and discussion with the analysis of how texts and discourse work, where, with what consequences, and in whose interests" (Luke, 2012, p. 5). Educators, we assert, can be principal actors in 
shaping such discourse, yet complementary research from a critical perspective too infrequently examines how educators' civic literacy practices can expand notions of civic participation (an exception is Payne, 2017).

Built into our critical literacy foundation is recognition that literacy practices are tied to individuals' civic identities and practices. For instance, civic education can position youth to "acquire and learn to use the skills, knowledge, and attitudes that will prepare them to be competent and responsible citizens throughout their lives" (Carnegie Corporation of New York \& CIRCLE, 2003, p. 4). This perspective foregrounds conventional practices of civic learning and participation, but--from a critical stance--does not account for cultural dimensions that shape the meaning and experiences of civic life across socioeconomic contexts. Opportunities for civic participation (Kahne \& Middaugh, 2008) and empowerment (Levinson, 2007) are substantially limited for many individuals due to socioeconomic, racial, and educational inequities (LadsonBillings, 2006). In response, we recognize the need to expand what counts as civic practice in a contemporary era of "participatory politics" whereby civic actors, whether youth or educators, can engage in "interactive, peer-based acts... to exert both voice and influence on issues of public concern” (Cohen, Kahne, Bowyer, Middaugh, \& Rogowski, 2012, p. vi). Our study joins growing efforts that examine civic practices facilitated by educators in diverse school contexts (Mirra, 2018) and that also support educator learning about critical democratic education (Payne, 2017). Our critical literacy perspective informs how we understand civic literacy as "communicative practices intentionally positioned to reflect upon and contribute to a sociopolitical world" (Garcia \& Mirra, in review). 


\section{Digital and Civic Literacy}

In our study, critical literacy perspectives are used to perceive and analyze digital interactions. Our theoretical approach is inclusive of critical digital literacies, or "those skills and practices that lead to the creation of digital texts that interrogate the world" (Ávila \& Pandya, 2013, p. 3). Critical digital literacy, we suggest, flourishes given the distributed nature of knowledge in participatory culture (Jenkins, 2006). From a critical stance, Ávila and Pandya (2013) note the possibility of upending "the role of the expert in critical digital literacies" (p. 6). Such perspectives highlight that critical literacy may be encouraged by digital tools and practices to further investigate and critique power. Such opportunities can help democratize how texts are produced and remarked upon as civic activity.

Both students and educators routinely exercise critical and digital forms of civic literacy to dialogue about the sociopolitical consequences and structural inequities of American education (Baker-Bell, Stanbrough, \& Everett, 2017; Share, 2015). Whether because of justified “political anger” (Ruitenberg, 2009) or disengagement from traditional civics education (Watts \& Flanagan, 2007), youth authorship of public civic writing--at times aided by adult educators and mentors--may be understood as "a form of learning fostered via participatory politics that emerges when young people achieve civic agency linked to their deeply felt interests, identities, and affinities" (Jenkins et al., 2015, p. 17). For instance, as a response to the February, 2018 school shooting in Parkland, Florida, students from Marjory Stoneman Douglas High School leveraged Twitter to advocate policy change, fact-check their detractors (sarahchadwickk, 2018), and critique politicians and media organizations. Stoneman Douglas High School students' public statements extend a lineage of critical civic literacy penned at the intersection of education, activism, and critique that connects the 1960 Student Nonviolent Coordinating 
Committee Statement of Purpose (National Humanities Center, 2007) to digital writing in contemporary social movements like \#BlackLivesMatter and \#ConcernedStudent1950. Like youth, the West Virginia educator strike (Slocum, Hathaway, \& Bernstein, 2018) demonstrated that educators also exercise similar digital and civic literacy practices (i.e. \#55strong) to provoke dialogue about political change.

\section{Annotation as a Digital and Civic Writing Practice}

As noted, our study examines how educators' use of digital annotation for personal, political, and pedagogical dialogue both expands what counts as civic participation and enlarges sites of civic practice. We perceive annotation from a critical and digital literacy perspective as a practice positioning authors and readers in collaborative and contested discourses that reflect and redefine power. From a perspective of critical civic literacy, we also approach annotation as a potentially powerful civic practice as the acts of writing over, around, and alongside texts can foster discussion about sociopolitical contexts (Kalir \& Perez, 2019). Reading, interpreting, and interacting via forms of web annotation may be interpreted as a contemporary form of digitized graffiti (e.g., Phillips, 1999). Nonetheless, the civic affordances of web annotation to combat misinformation (Udell, 2017) and encourage a pedagogy of "democratic deliberation" (Schacht, 2015 ) indicate promising aspects of such writing. In defining critical digital literacy, Ávila and Pandya (2013) warn against a blind faith that all digital tools are "inherently empowering" (p. 6). Indeed, recent scholarship and political events emphasize how digital tools invisibly reify power structures and further oppress historically marginalized groups (Eubanks, 2018; Noble, 2018). Like all types of writing, digital annotation may be both harmful and liberatory as it is layered atop online text as a publicly accessible and editable "wall." Within broader critical and digital literacy practices, however, we understand web annotation as encouraging collaborative writing 
practices that can transform conventional texts into civic contexts, or new sites for civic expression and dialogue.

The promising civic writing practices associated with annotation necessitate that we briefly highlight particular affordances of open web annotation (OWA). OWA is defined by three qualities of the open web (Kalir, 2018): Open standards, including technical specifications for standardized annotation architecture (Whaley, 2017); open principles, such as accessibility, decentralization, and transparency (Berners-Lee, 2010); and open practices that help create open educational resources and encourage open educational practices (DeRosa \& Jhangiani, 2017). OWA echoes how new media engender fluid authorship, the digital composition of ideas and identities, and the "layering" of multiliteracies "to contextualize, individualize, and characterize information and meaning" (Cope, Kalantzis, \& Abrams, 2017, p. 38). As noted, not all OWA is civic writing; nonetheless, forms of civic writing engaged with and through OWA are inherently tied to multiple and multimodal texts. Furthermore, an interrogation of the relationship between authors and readers (Barthes, 1977), and between published texts and readers' activity, is a reminder that OWA can advance both digital and critical media literacy practices. In these respects, OWA can transform texts--including, as we will discuss in this article, texts like academic scholarship--into participatory contexts for civic activity and expression.

This study examines a specific "wall" of online text, annotation-driven writing authored by educators, and the ways in which educator practices and understandings multiplied across one text as a civic context for personal, political, and pedagogical dialogue. 


\section{Method}

\section{The Marginal Syllabus: A Social Design Experiment}

This study of educators' civic writing on a digital wall is associated with a political project "organized around the development of an equity-oriented, humanist research agenda" (Gutiérrez \& Vossoughi, 2010, p. 102). Since 2016, the Marginal Syllabus has embraced social design experiment methodology (Gutiérrez \& Jurow, 2016) to convene and sustain openly accessible online conversations with educators about equity in education. Like a book club, the project's name, design, and programming embrace multiple interpretations of the term marginal. First, the project partners with authors whose writing is contrary, or marginal, to dominant education norms. Second, the Marginal Syllabus facilitates public conversation among educators as they write in the margins of partner authors' texts using OWA. Third, educator conversation is mediated by Hypothesis, an open-source web annotation technology created by the eponymous non-profit organization that is marginal to commercial (educational) technology. The project's equity-oriented leverages the open web, fosters multi-stakeholder partnerships, features open content, and engages professional learning as an open educational practice (Kalir, 2018).

The Marginal Syllabus is hosted by the National Writing Project and has also partnered with the National Council of Teachers of English to organize author partnerships and access to scholarship. Each month, K12 classroom teachers, pre-service teachers, and higher education faculty are invited--through social media, word-of-mouth, and professional networks--to read and annotate a partner author's text. Educators primarily represent humanities and social sciences disciplines and, as "text-participants" (Serafini \& Gee, 2017), share reactions, interpretations, and divergent views through OWA. The 2017-18 Marginal Syllabus, for example, explored the theme "Writing Our Civic Futures;" it featured nine conversations, 13 
partner authors, and, on average, engaged 18 educators for 14 days of OWA conversation (Table

1). Eighty-seven individual educators participated in the 2017-18 syllabus, and 17 contributed during three or more conversations.

Table 1: Summary of 2017-18 “Writing Our Civic Futures” Marginal Syllabus

\begin{tabular}{|c|c|c|c|c|c|}
\hline Month & Partner Author(s) & Topic & $\begin{array}{l}\text { Participating } \\
\text { Educators }\end{array}$ & $\begin{array}{l}\text { Hypothesis } \\
\text { Annotations }\end{array}$ & $\begin{array}{l}\text { Active } \\
\text { Days }\end{array}$ \\
\hline October ' 17 & Henry Jenkins & $\begin{array}{l}\text { Youth digital } \\
\text { activism }\end{array}$ & 15 & 84 & 12 \\
\hline November ' 17 & $\begin{array}{l}\text { Nicole Mirra and } \\
\text { Antero Garcia }\end{array}$ & $\begin{array}{l}\text { Civic imagination } \\
\text { and innovation }\end{array}$ & 27 & 211 & 16 \\
\hline December ' 17 & Linda Christensen & $\begin{array}{l}\text { Critical literacy and } \\
\text { student lives }\end{array}$ & 32 & 206 & 25 \\
\hline January ' 18 & Danielle Allen & $\begin{array}{l}\text { Political equality and } \\
\text { freedom }\end{array}$ & 12 & 62 & 10 \\
\hline February ' 18 & $\begin{array}{l}\text { Joseph Kahne and } \\
\text { Benjamin Bowyer }\end{array}$ & $\begin{array}{l}\text { Student media } \\
\text { literacy }\end{array}$ & 21 & 99 & 16 \\
\hline March '18 & $\begin{array}{l}\text { April Baker-Bell, } \\
\text { Raven Jones } \\
\text { Stanbrough, and } \\
\text { Sakeena Everett }\end{array}$ & $\begin{array}{l}\text { Critical media } \\
\text { literacy, pedagogies } \\
\text { of healing }\end{array}$ & 20 & 150 & 15 \\
\hline April ' 18 & Erica Hodgin & $\begin{array}{l}\text { Online civic and } \\
\text { political dialogue }\end{array}$ & 7 & 55 & 6 \\
\hline May '18 & Steven Zemelman & $\begin{array}{l}\text { Social action and } \\
\text { project-based } \\
\text { learning }\end{array}$ & 14 & 109 & 14 \\
\hline June ' 18 & Troy Hicks & $\begin{array}{l}\text { Future of digital } \\
\text { writing }\end{array}$ & 17 & 148 & 12 \\
\hline
\end{tabular}

The Marginal Syllabus is a social design experiment committed to designing and researching sociopolitical learning opportunities for educators (Kalir \& Perez, 2019). Social design experiments are informed by methodological developments in design-based research and 
practitioner inquiry, and are a democratizing form of research oriented toward inquiry, equity, and change. The Marginal Syllabus design team--comprised of K12 educators, researchers, and organizational leaders--has concertedly enacted equity commitments through multiple participatory strategies. First, partnerships with authors, academic publishers, and organizations turn scholarly texts into civic contexts for public conversation. Second, our social design experiment positions texts as a digital "commons" for shared annotation (e.g., Beach, 2012). Third, educators' OWA discussions are facilitated as emergent counternarratives to discourses about educational inequity. The Marginal Syllabus echoes other social design experiments that have foregrounded equity commitments by co-designing technology-rich learning, expanding sites of civic activity, and broadening forms of public civic practice (Taylor \& Hall, 2013).

Ethical and transparent research procedures are another equity commitment of this social design experiment. Multiple online resources, including the project website and blog posts, inform participating educators that: a) Marginal Syllabus programming is associated with university-approved research; b) public Hypothesis annotations are contributed to the public domain via a Creative Commons dedication and may therefore be used for research; and c) neither Hypothesis nor ongoing research collects educators' personally identifiable information. ${ }^{1}$ Significantly, educators are valued project stakeholders who regularly influence text selection, facilitate discussion, and contribute to research (Kalir \& Dillon, in press). Marginal Syllabus research is a direct response to the need for ethical, equity-oriented design and inquiry at the intersection of the learning sciences and open education (Kalir, 2018).

\footnotetext{
${ }^{1}$ Marginal Syllabus conversations are public. Hypothesis' Terms of Service attribute a Creative Commons CC0 Public Domain Dedication to all public annotations. Accordingly, educators' Hypothesis usernames--some of which are anonymous--have not been changed into pseudonyms for this study. Some minor edits have been made to quoted annotations to remove personally identifiable information.
} 


\section{Data Collection and Analysis}

It is appropriate to study particular cases of learning within a social design experiment (Gutiérrez \& Vossoughi, 2010). Our case is bound by educators' OWA during the November, 2017 Marginal Syllabus conversation. Why this conversation? Another equity commitment of this study concerns our authorship and co-production of civic writing. All Marginal Syllabus conversations are predicated upon consent to annotate. Partner authors and, in some cases, their publishers agree to have scholarship openly accessible and publicly annotated using Hypothesis. The focal text for the November, 2017 conversation, co-authored by Garcia (Mirra \& Garcia, 2017), discusses expansive notions of civic interrogation and innovation. Kalir is a member of the Marginal Syllabus design team and helped facilitate the conversation. The 211 annotations contributed by 27 educators and collected for this study include OWA written by Kalir and Garcia’s co-author Mirra. We approach our intersecting roles in the Marginal Syllabus and within this case as a methodological strength that highlights our overlapping commitments as designers, researchers, and participants. As researchers, our qualitative analysis of the 211 annotations began with "descriptive coding” (Saldaña, 2016). This first-order strategy is appropriate for exploratory studies and allowed us to identify broad categories associated annotations that: a) displayed conventional marking strategies (Marshall, 1997); b) pertained to civic interrogation and innovation; c) aided facilitation (primarily by Kalir); and d) were authored by regulars, newcomers, and Mirra as partner author.

Discourse analysis. Following broad descriptive coding, we analyzed educators' civic writing using two discourse analysis tasks (Gee, 2011, 2014). Each task examined, as our unit of analysis, individual annotations during the focal conversation. This unit of analysis allowed us to examine how educators' OWA evidenced civic writing practices. First, we adopted Gee's (2011) 
situated meaning task to discern how educators conveyed specific civic meanings through OWA. Both words and phrases, according to Gee, can exhibit "different and specific meanings in different contexts in which they are used and in different specialist domains that recruit them" (p. 152). Our second discourse analysis task attended to political dynamics present in educators' annotation. Gee (2014) suggests that critical approaches to discourse analysis can reveal how power, status, solidarity, and conflict function within a given discourse and reflect broader ideologies (see also Fairclough, 2013). For Gee (2014), the task of critical discourse analysis is to identify how "value-laden" statements, such as those made via OWA, appear within and influence dialogue. We inductively coded all annotations to ascertain, first, how situated meaning was present in educators' civic writing and then, from a critical stance, to discern how educator statements were political in content or function. Emergent codes resulting from both discourse analysis tasks were refined to create categories through iteration and comparison to counter-examples in the data. We identified and then categorized a repertoire of ten civic writing practices present in the conversation by attending to both situated meaning and political expression. During analysis, the ten categories and sample data were shared at a conference and via blog post to gather feedback from colleagues and invite educators to member-check our initial interpretations.

To illustrate our analytic approach--applying the situated meaning and political expression tasks, then categorizing educators' annotation patterns--consider one sample conversation thread. This thread includes one in-line annotation and two replies written by different educators. The initial annotation, by reruhlen, was annotated to a passage discussing how "youth interests and online social forums have the potential to become the seeds of 21 st- 
century collaboration and organization around political interests" (Mirra \& Garcia, 2017, p. 146).

The thread also appears as Figure $1 .^{2}$

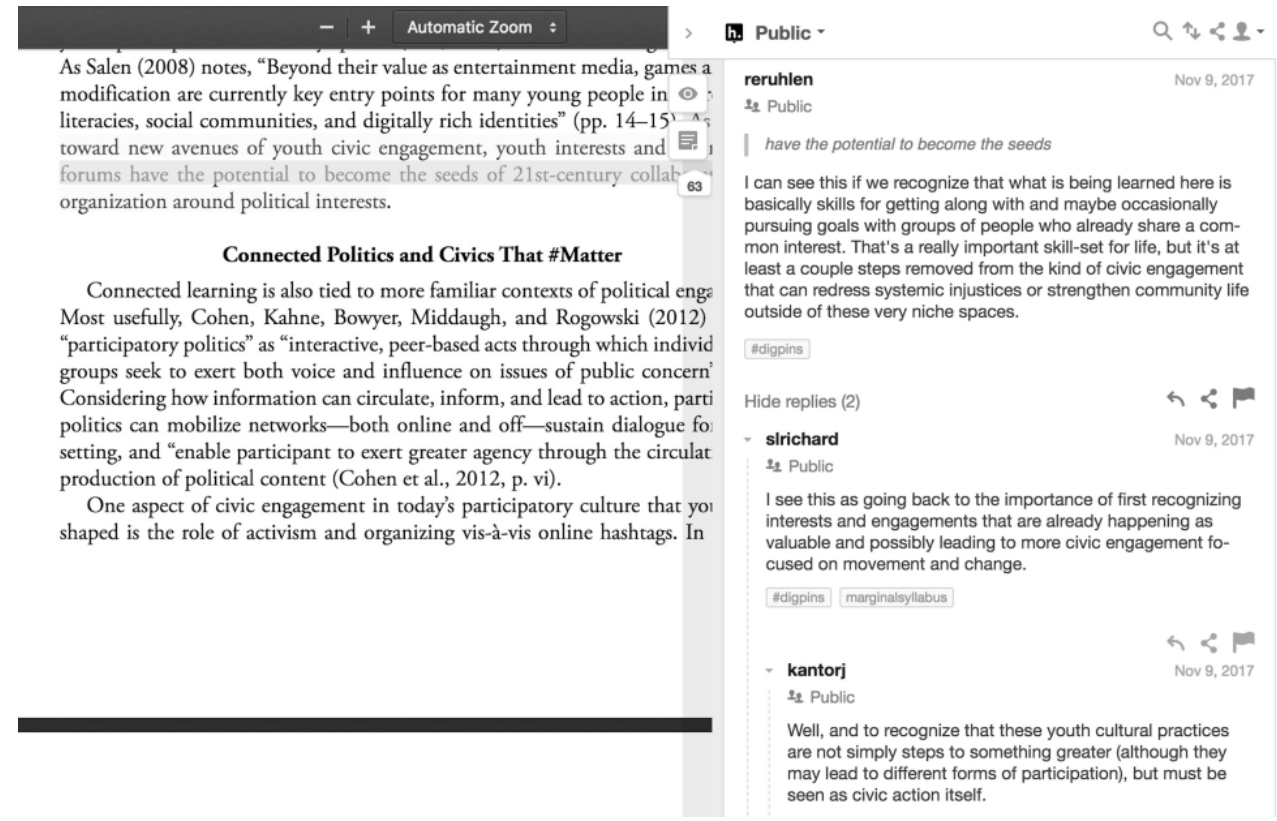

Figure 1: Screenshot of sample thread with three annotations displayed with focal text.

reruhlen: I can see this if we recognize that what is being learned here is basically skills for getting along with and maybe occasionally pursuing goals with groups of people who already share a common interest. That's a really important skill-set for life, but it's at least a couple steps removed from the kind of civic engagement that can redress systemic injustices or strengthen community life outside of these very niche spaces.

slrichard: I see this as going back to the importance of first recognizing interests and engagements that are already happening as valuable and possibly leading to more civic engagement focused on movement and change.

kantorj: Well, and to recognize that these youth cultural practices are not simply steps to something greater (although they may lead to different forms of participation), but must be seen as civic action itself.

In this thread, we coded for the different situated meanings and the perceived values of “engagement." Initially, reruhlen distinguished civic engagement from less consequential youth

\footnotetext{
${ }^{2}$ The indentation structure of transcribed annotations resembles Hypothesis' threaded organization of annotations and replies.
} 
interest ("it's at least a couple steps removed") and attributed more value to engagement that redresses "systemic injustice." In contrast, "engagements" that "are already happening" (slrichard) and "youth cultural practices" that are "civic action itself" (kantorj) were perceived as valuable regardless of future outcomes (kantorj: "not simply steps to something greater"). These three annotations evidence shifting situated meanings about the definition and purpose of youth civic engagement. Furthermore, the annotations illustrate political expression as educators debate and place differential value on particular youth interests and actions.

Examining situated meaning and political expression in this thread helped identify two categories of civic writing: Unpacking, or questioning assumptions about civic engagement; and evaluating, or critiquing claims about civic engagement. Our analysis ultimately categorized ten civic writing practices that we propose as a repertoire enacted by educators in this particular conversation. In our findings we present this repertoire of civic writing--referred to by the acronym SUBLIMATES--as a contribution to understanding the composition, meaning, and deliberation of civic writing on digital walls. These civic writing practices echo educator critique, debate, and questioning identified in discourse from the 2016-17 Marginal Syllabus (Kalir \& Perez, 2019) and educators' ethical dialogue from the March, 2018 conversation (Kalir \& Dillon, in press).

Researcher positionality. Our overlapping roles in the Marginal Syllabus necessitate that we acknowledge complicated subject positions. We have each sought to manage how our power and privilege informed participation in the focal conversation and, subsequently, in our analysis of the conversation as researchers. Kalir was attentive to intersecting dynamics among his social and facilitative presence during online conversation (Kozan \& Richardson, 2014), and, rather than occupy digital space with lengthy exposition, provided technical assistance, shared 
links to resources, and asked open-ended questions. Garcia did not participate in the annotation conversation but, as co-author of the focal text, carried a distinctive authority about the text, related topics, and discursive interpretations into our analysis. Additionally, we are each former K12 classroom teachers and current teacher educators. We are accustomed to facilitating and analyzing conversation, whether within classroom or online settings. Nonetheless, in writing about this case we worked to question our biases about what counted as productive and meaningful civic discourse. Educators participating voluntarily in the Marginal Syllabus were not our students; rather, they were peers whose professional opinions and interpretations remain as valid as our own. There is no doubt that we brought multiple political stances to this work given our formal roles, personal backgrounds, sociocultural identities, and professional responsibilities. A civic interrogation would be incomplete were we not to critically interrogate our biases, question conclusions, and note the limitations of our research design.

Limitations. First, our analysis concerns only the November, 2017 conversation, one of nine comprising the 2017-18 Marginal Syllabus. We analyzed a corpus of 211 annotations that account for approximately one fifth (19\%) of the 1,124 OWA across all conversations. Second, our proposed civic writing repertoire should be understood only as a description of discourse for one conversation and not as a standard of either educators' OWA or their civic writing (despite resonance with analyses of educator participation in other Marginal Syllabus conversations). It is to be determined whether the ten civic writing practices we identify may also be found in other digital discourses. Future research should: a) confirm, or revise, how this particular civic writing repertoire appears in other OWA contexts; and b) investigate whether this repertoire explains educators' civic writing beyond OWA contexts. Third, our concern for civic writing meant that 
our analysis ignored some OWA functions, such as conventional annotation practices like highlighting or placemarking (Marshall, 1997).

\section{Findings}

We report ten civic writing practices that describe how educators annotated during the November, 2017 Marginal Syllabus conversation. This civic writing repertoire details patterns that reflect shifting situated meanings and political expressions present in educators' OWA. Again, it is feasible that similar civic writing practices may characterize educator annotation of other texts, as well as written commentary in other digital contexts. Nonetheless, we contend that this descriptive repertoire is useful as it emerged through educators' interest-driven participation in an open learning activity, demonstrates how educators used OWA to mediate civic writing on a digital wall, and helped educators spark a critical conversation about civic engagement.

We embrace the heuristic of an acronym to name and organize ten civic writing practices present in the focal annotation conversation. We draw upon the word sublimate--a verb evoking transition and elevation, and that exhibits different situated meanings across cultural and scientific contexts--as an illustrative term-turned-acronym. The heuristic SUBLIMATES is our attempt to cohesively describe ten practices that emerged as educators' civic writing from the broader OWA corpus. The ten civic writing practices are: Summarizing, Unpacking, Building, Linking, Illustrating, Musing, Affiliating, Translating, Evaluating, and Sharing. This civic writing repertoire functioned, at times irrespective of OWA content, to mediate educator participation in their annotation conversation. Each of these practices will be discussed as having sublimated educators' civic writing to foster consequential--and critical--civic literacy. In the following sections we define each of the ten annotation practices comprising SUBLIMATES. 
We draw upon our discourse analysis tasks to illustrate how educator annotation, as civic writing on a digital wall, helped develop critical civic literacy.

\section{Summarizing}

Educator OWA functioned to summarize, or review and restate, civic topics associated with the conversation text. Summarizing often appeared in educators' initial in-line annotations, rather than replies, and functioned to emphasize why an idea or insight was deemed important. For example, an observation by Mirra and Garcia (2017) regarding the ideological constraints of traditional civic engagement delineating "who does and does not count as a good citizen" (p. 142) was revoiced by ccantrill "highlighting" and summarizing the core argument: "Highlighting the ideological aspect and the impact of that in excluding and narrowing our vision of what it means to be a citizen." Another characteristic of summarizing was length; educator OWA that summarized were often short. dogtrax's pithy "A shift..." was annotated to a lengthy passage about students' changing use of social media as innovative civic action. The political purpose of summarizing was apparent as educators revoiced, via OWA, certain ideas and, consequently, indicated that these ideas mattered to them and the conversation.

\section{Unpacking}

Educators authored OWA to unpack--or critically question--assumptions about how civic engagement was defined and practiced. Unpacking served an important political role within the annotation conversation as educators used this type of questioning to indicate that a civic term or practice could be questioned or critically assessed. Unpacking appeared in a thread that responded to literature about the "civic achievement gap" (Levinson, 2007). In Mirra and Garcia's (2017) assessment, a limitation of this literature was that it "persists in placing the onus of responsibility on them [youth] for not 'achieving' civically" (p. 141). 
szemelman: Anyone reading the whole of Levinson's book, "No Citizen Left Behind" will know that she grapples deeply with the systemic conditions that make social advocacy and action for change difficult for minority students, and with the contradictions in the education system that a teacher and students must deal with. Of course, perhaps she didn't say everything exactly as these authors might approve of.

dogtrax: Does the digital make such advocacy for minority students easier? More effective?

nicolemirra:@szemelman: Thanks for your annotation! I agree that Meira does a great job of detailing the barriers that stand in the way of student action. I also know that she has since problematized the language of the civic achievement gap - we just wanted to point out the assumptions that go with that phrase. Can't wait to see more of your thoughts!

Multiple assumptions about civic engagement were unpacked in this thread. szemelman unpacked pedagogical and political implications of civic engagement, noting "contradictions in the education system that a teacher and students must deal with.” dogtrax questioned the effectiveness of "the digital" for certain students. And Mirra unpacked the scholarly context of a key phrase ("she has since problematized the language of the civic achievement gap"), and also explained her authorial intent: "We just wanted to point out the assumptions that go with that phrase." Throughout, educators unpacked qualities of civic engagement while also demonstrating how to critically question the very terms that defined their discussion of civic engagement.

\section{Building}

Educators used OWA to build connections from the focal text and conversation to related civic contexts and concerns. Building connections across texts and contexts occurred when, for example, youngwhan contributed an in-line annotation to the word "Dream," a reference to Coates' (2015) critique that the American Dream is not virtuous but inherently problematic. youngwhan observed: "I'm also reminded here of another prominent narrative/myth - that of meritocracy." youngwhan built by referring to rap lyrics that describe America as a "melan- 
ocracy;" the annotation connected together Mirra and Garcia's (2017) article, Coates' Between the World and Me (2015), and rap lyrics to criticize the meaning and practice of meritocracy across multiple texts and sociopolitical contexts.

Educators' practice of building also co-constructed commentary about important civic concerns. A representative annotation thread emerged in response to a statement by Mirra and Garcia (2017) that "opportunities for learning about civic engagement are no longer tethered to traditional spaces like classrooms" (p. 145). Three participants progressively built insight and surfaced complexity about civic activity outside formal schooling. Civic activity outside "traditional settings is difficult work" (dogtrax), may require alternative approaches to facilitation that "engage adults... beyond the traditional teacher role models" (tutormentor1), and yet indicate promising opportunities for "research... that schools might borrow" (ltwiss). Building connections among civic texts and contexts, and building commentary about civic concerns, afforded educators an opportunity to draw upon their professional experiences and demonstrate expertise.

\section{Linking}

Educators included hyperlinks in OWA content to link the focal text with related civic content. Linking established Bush's (1945) "associative trails," a key feature of annotation among networked information environments. Educators' 42 hyperlinks tethered the text to various resources of civic relevance, including: News media reporting by the Washington Post, the Guardian, and other publications; reports by research groups; scholarship about topics like youth participatory action research; and YouTube videos featuring academics and public intellectuals speaking about civic engagement. 
bakerdoyle, for example, linked Mirra and Garcia’s (2017) discussion of digital technologies affording youth new forms of civic action to a related book: "This also makes me think about what Tufekci wrote about in her book, Twitter and Teargas - tracing how the digital has impacted/reshaped activism in several social movements around the globe https://www.twitterandteargas.org/." There were also three instances of annotations linked to a previous Marginal Syllabus conversation, as with onewheeljoe's annotation critiquing so-called "best practices" in civic education: "This connects back to another piece co-authored by Garcia featured in last year's \#marginalsyllabus which pointed out the way notions of best practice are problematic." Educator linking showcased civic interests and prior knowledge while positioning the focal text as situated among, and connected to, associated civic texts and contexts.

\section{Illustrating}

Illustrating occurred when educators used annotation to explain the pedagogical or political relevance of a civic topic. Educators' illustrating included, perhaps not surprisingly, examples and evidence drawn from their professional experience or sociopolitical context. Multiple instances of illustrating appeared in a conversation composed in response to Mirra and Garcia's (2017) observation that "students are over twice as likely to study 'great American heroes and the virtues of the American form of government' in their social studies and civic courses than problems facing the country" (p. 137). The following excerpt from a longer thread shows three educators illustrating the pedagogical and political complications of formal civics education.

onewheeljoe: Interestingly, in 2014 here in Colorado, the Jefferson County School board proposed a "curriculum committee that would call for promoting "positive aspects" of the United States and its heritage and avoiding material that would encourage or condone "civil disorder, social strife or disregard of the law.' It is noteworthy that education leaders working within the legal civic frameworks of our system can actively try to whitewash American history. Hence the call for interrogation... 
andreaz: As an ELA teacher, I had never considered how civics is approached in classrooms. Reading American Dream themed novels (Great Gatsby, etc) always struck me as "dream crushing" ... Interesting to think about the ways in which curriculum standards either implicitly or explicitly take a stance on such things.

LeeshaFord: It is interesting as schools do whitewash history. So few teach about the internment camps of WWII, as it is just a line or two in the history book.

Educator illustrating, in this exchange, referenced local educational and political circumstances (onewheeljoe), troubled interdisciplinary perspectives, texts, and standards (andreaz), and affirmed that schools and curricula "do whitewash history" (LeeshaFord). Illustrating functioned to assert authority as educators wrote about professional experiences and opinions.

\section{Musing}

Educators used OWA to muse, or to ask broad, open-ended questions inspired by civic topics. Musing was not synonymous with all manner of questioning, such as inquiring for clarification or questioning assumptions (i.e. unpacking). Rather, musing signaled that an idea was open for interpretation or that it was generative to state, and discuss, a broader question. For example, at the beginning of Mirra and Garcia's (2017) article they qualify their meaning of "citizen" and "civic;" both terms eschew legal status in favor of describing how individuals "participate fully in civic communities at local, national, and global levels regardless of age or legal residency" (p. 138). This prompted educators to muse about the meaning of "citizen" and related concerns about youth, citizenship, and education.

SarahLW: What does it mean to be a citizen? in what ways does the term overlap with legal status, and in what ways does it not? That's a powerful question!

onewheeljoe: Important to note that we teach students of color to aspire to participate in systems that have historically sought to disenfranchise them, or would label them "illegal." We fail to recognize the ways those communities do engage. 
remikalir: Upon whose terms are notions of citizen defined and exercised? And what forms of agency do youth leverage to (re)define citizenship so as to meet their needs, express their interests, pursue their goals? These are some of the questions Nicole and Antero's article raises for me.

dogtrax: Good point. So, how do we recognize participation when we don't have the lenses to see it? Who will teach the teachers? (We could turn to our students)

Questions in this thread evidence educators progressively musing about the meaning of citizen: How it might "overlap with legal status" (SarahLW); who has power to define and exercise citizenship (remikalir); and the ways in which educators might learn to better "recognize participation when we don't have the lenses to see it" (dogtrax). These examples of musing were characterized by collective curiosity, exploratory consideration ("Who will teach the teachers?"), and reflective recognition that open-ended questioning was a valuable feature of the conversation (“That's a powerful question!").

\section{Affiliating}

Educator affiliating strengthened connectedness among text-participants through metalanguage, jokes, and multimodal expression. Educator meta-language--or OWA that explicitly referenced discourse features--was also used to affiliate with the focal text. youngwhan, for example, responded to Mirra and Garcia's (2017) question "What story lines can inspire civic action when the narrative of the Dream does not resonate?" (p. 138) with an unambiguous reference to the experience of text-participation: “I'm feeling this question. Stories are so important." Other instances of affiliating were multimodal. When educators included images for emphasis, such multimodality strengthened social interaction. dogtrax's use of a political cartoon to critique the American Dream established visual and ideological affinity with the text. szemelman's reply suggested such annotation reinforced social connectedness: "Cool graphic." 
Similarly, thefieldworker's "Long Live Resistance Auntie" image and reference to "the Women's March" and "Charlottesville" was a reply to marisgillette who observed "the disappointment, frustration, and rage that we see publicly performed in many venues, particularly since Trump was elected." thefieldworker's multimodal and provocative annotation was a sign of solidarity with marisgillette. The practice of affiliating suggests the value of social presence and connection when participating in civic conversation.

\section{Translating}

Educator translating framed civic ideas from the focal text within other academic, political, and pop culture discourses. Among the annotations contributed to the conversation was a remark by tayken that bridged Coates' (2015) civic observations to the work of comedian and author Trevor Noah: "I highly recommend Coates and Noah in tandem. I inadvertently collided their writings and the resulting effect was profound (refracted perspective)." An instance of translating to another academic context appeared in response to Mirra and Garcia's (2017) criticism of scholars who adopt a "deficit" perspective about civic engagement and "locate the failure of engagement in those communities themselves" (p. 141). johnclawless wrote: "Tommie Shelby has a new book out on the ways in which we respond to the geography of inequality, critiquing in particular what he calls 'the medical model'... The deficit approach seems to fit squarely within this model, and it might be productive to read this piece in conversation with Shelby's book." johnclawless' translating named a scholar and relevant resource (Shelby, 2016), and explicitly noted how Mirra and Garcia's (2017) critique aligned with both the cited content and possible collaborative activity ("it might be productive to read this piece in conversation with Shelby's book"). Educator translating also included annotations that featured: Embedded YouTube videos, as with jeremydean's "Check out Safiya Noble's work on 'Algorithms of 
Oppression;"' links to personal blog posts; and references to other cultural discourses, like kantorj stating "This is also seen in the 'grit' narrative." These annotations demonstrate how educator annotation expertly translated content from one source to related civic conversations and contexts.

\section{Evaluating}

Evaluating was a means of critiquing specific civic claims and comments. Educators' evaluative annotations pushed back against an original statement or analysis by the partner authors. Evaluating also included disagreement that shaped commentary among educators. A notable instance of both dynamics--educators adopting a critical stance toward the text and also toward other annotations about the text--arose in response to Mirra and Garcia's (2017) assertion that "our analysis suggests the need to actually move beyond practices of civic participation and toward practices of civic interrogation and innovation" (p. 139). The following excerpt begins a longer thread that totaled 11 annotations by six educators.

jeremydean: I don't want to speak too soon, but this concerns me. I'm all for imagining new kinds of civic participation or "innovation," but at some point there needs to be a connection to the established means of engagement and action, right? If everyone is just Tweeting and not marching or Tweeting and not voting, then we have a kind of virtual movement.

tayken: Speak too soon, speak too soon! I'm honestly not clear on what this next step would look like without clear ties to what civic partic. has traditionally been.

Sarah $L W$ : it seems like this is calling out the idea of merely participating in structures that are broken, to thinking about how to interrogate those broken structures and innovate new ways of forging change.

This thread subsequently featured: An exchange between jeremydean and kantorj debating the merits and limitations of "conventional citizenship;" and, later, a challenge to jeremydean's emphasis on "both/and" social change from onewheeljoe who noted that "'Both/and' solutions 
might not acknowledge how treacherous traditional modes of participation are for some." The interactional politics of educator expression were particularly acute when evaluating. Evaluating claims and comments showcased divergent perspectives, revealed priorities, and positioned the text's margins as a contested, rather than neutral, discursive space.

\section{Sharing}

Educator sharing communicated information about personal lives and values. This annotation practice often featured educators blurring distinctions between their personal and professional contexts. Among representative examples, braunkm wrote an annotation in response to Mirra and Garcia's (2017) claim that "schools and community organizations... fail to educate all communities equally" (p. 141): "I know personally, I do not feel that I learned enough in school about civic responsibilities and knowledge. I wish that this type of education started at a younger age, instead of middle and high school." Another example of sharing, authored by youngwhan, also drew from personal and professional perspectives: "This is why in Oakland, we commit to preparing students to be college, career, and community ready. Citizenship is too limited and as a legal term limits many members of the community." Sharing annotations suggest educators developed a level of comfort whereby it was acceptable to voluntarily write about personal information. Moreover, such sharing helped create an inclusive public forum for civil conversation about civic topics.

\section{Discussion}

This study examined how collaborative discussion associated with the Marginal Syllabus, a social design experiment, encouraged educators' civic writing on digital walls. We detailed how discourse patterns within interest-driven professional learning --as afforded by the social and technical features of open, collaborative, and civically-oriented web annotation--sublimated 
everyday writing practices like summarizing, translating, and evaluating. We do not presume that the ten SUBLIMATES practices align with specific civic dispositions or identities. Instead, we named and shared these practices retrospectively as a vocabulary to understand the rich and expanded "multi-dimensional space" (Barthes, 1977) of civic writing that developed and was deliberated during one annotation conversation. Here, our discussion addresses the broader significance of this repertoire of civic writing practices. Specifically, we consider implications for: Theorizing the marginality of critical civic literacy; designing learning environments that foster educators' civic writing; and implementing and facilitating learning opportunities that encourage educators' civic writing across digital walls.

\section{Marginality and Critical Civic Literacy}

Our case of educators' civic writing suggests it may be generative to further theorize annotation as enabling discourse among marginal digital spaces and social relations. If, as suggested, everyday digital and collaborative annotation practices like linking or illustrating foster new and critical civic writing practices, then we further argue such annotation can be conceptualized as "imminently hybrid, that is, polycontextual, multivoiced, and multiscripted" (Gutiérrez, Baquedano-López, \& Tejeda, 1999, p. 287). As instantiated through OWA, educator practices like unpacking and musing emerged as technically and discursively hybrid. The hybridity of annotation conversation in digital learning environments like the Marginal Syllabus indicates such polycontextual spaces sustain multivoiced writing and critical interaction among civic actors, including educators. SUBLIMATES, a repertoire of ten civic writing practices afforded by OWA, amplified and reinscribed the marginality of educators' civic dialogue, demonstrating why it is useful to conceptualize the hybrid qualities of critical civic literacy. 
The ubiquitous marginality of the Marginal Syllabus' social and technical relations, alongside educators' hybrid civic writing practices, further suggests that learning environments fostering critical civic literacy be theorized as intentionally designed third spaces (Gutiérrez, 2008). Hybridity and third space have been embraced by scholars investigating digital literacy and learning across formal and informal environments (Levy, 2011; Morgan, 2010). However, much of this research concerns the literacy practices of children and youth, rather than educators. SUBLIMATES, as a distributed repertoire of civic writing practices, indicates that annotation may be understood as a multivoiced and dialogic activity relevant to multiple sociopolitical contexts, including educators' personal, professional, and political lives. Furthermore, educators' collective OWA among digital margins opened a third space for shared civic inquiry through building, affiliating, and unpacking. We encourage future scholarship to theorize how social design experiments, like the Marginal Syllabus, foster hybrid and critical literacy in third spaces that emerge as new civic sites between sociopolitical texts and contexts.

\section{Learning Environments and Civic Writing}

Our study of educator learning in the Marginal Syllabus is possible because the public project remains rooted in the equity-oriented commitments of a social design experiment. The humanizing and explicitly disruptive aims of social design experiments--aims which ultimately seek "fundamental social transformation" (Gutiérrez \& Jurow, 2016, p. 566)--are important to center when designing online and open learning environments that, under ideal conditions, foster educators' civic writing. How, though, to design (and subsequently research) learning environments that actively encourage such critical musing or sharing? Our case demonstrates the advantages of an expressly digital approach to sustaining both the partnership, programming, and inquiry of a social design experiment. The Marginal Syllabus drew upon the affordances of 
digital infrastructures, from public blogs hosting openly accessible texts to standards-based OWA technology, to create conditions whereby educators could easily experiment with and express their civic writing. Our digital strategies also facilitated an expanded capacity to elicit and make use of feedback from educators, conduct member-checks, and mitigate shortcomings in either facilitation or research. Social design experiments are, in our assessment, a generative methodological stance from which to foreground how digital tools, learning processes, and data help architect learning environments that foster educators' civic writing and discursive practices.

We also recognize how this case affirms a set of design principles for the creation of open, equity-oriented learning environments that support educators' civic writing. In related research, Kalir (2018) has described how the broader arc of Marginal Syllabus growth and programming is rooted in four sociotechnical design commitments: Leveraging the open web, fostering multi-stakeholder partnerships, working with open access content, and engaging educator professional learning as an open practice. Of course, it is conceivable that civic writing occurs by happenstance among publicly accessible learning opportunities or because digital environments encourage open annotation. Nonetheless, our study indicates why learning environments that seek to foster dialogue, critique, and shared inquiry--as well as the longer-term development of critical civic literacy--reflect participatory design principles (Hodgin, 2016). Such an orientation to critical civic activity is especially important when supporting participatory and equitable learning design (Teeters, Jurow, \& Shea, 2016). Advancing equity-oriented design principles is a necessary methodological commitment if open learning environments, especially for educators, are to transcend abstract mention of broadened access and participation (Reich \& Ito, 2017) and, rather, concretely encourage digital and critical civic literacy. 


\section{Facilitating Educators' Civic Writing}

The Marginal Syllabus has been designed as--and continues to support--openly accessible learning for educators eager to write about and discuss equity in education. Educators voluntarily embraced OWA as a means for their collaborative discourse. The civic writing practices comprising SUBLIMATES are, as noted, descriptive of both unscripted and also multiscripted conversation. Such improvisation presented challenges and tradeoffs as we facilitated and researched educators' civic writing practices. We did not examine, for example, educators' social annotation as distinct from the civic writing practice of affiliation. We also did not analyze the ethical qualities of educator annotation (see, however, Kalir \& Dillon, in press), or whether the practices comprising SUBLIMATES evidence ethical civic discourse. Moreover, we did not distinguish the prevalence of civic writing practices between regular and newcomer participants, nor did we consider how our facilitation moves may have prompted certain practices from either group of participants. While we appreciate how the Marginal Syllabus encouraged educators' civic writing and interest-driven learning as an alternative to formal professional development, we recognize that contingencies and inevitable limitations raise questions about how to facilitate accessible and meaningful learning whereby educators illustrate, translate, and evaluate civic content. Future research might pursue how collaborative OWA conversation complements learning in more formal educational contexts. Given that educators are key stakeholders, how might openly accessible and equity-oriented Marginal Syllabus conversation align with both teacher education and professional development efforts? And how can researchers, partner authors, and educators identify and share facilitation strategies that promote civic writing on digital walls, whether such writing is mediated by OWA or other sociotechnical practices? 
Questions about whether, and how, initiatives like the Marginal Syllabus should be incorporated into more formal learning contexts, such as teacher education courses, are logistically feasible and ethically complicated. Pragmatically, teacher educators can identify Marginal Syllabus texts and conversations that align with established curricula, assist students in using Hypothesis for OWA, and orchestrate either online or in-class activities related to social reading and civic dialogue. Anecdotal evidence suggests that teacher educators and pre-service teachers have meaningfully participated in Marginal Syllabus conversation. Nonetheless, it remains to be seen how teacher educators facilitate such openly accessible and open-ended learning. There is a remarkable difference between encouraging participation so as to model emerging forms of interest-driven learning and requiring participation that may be assessed and, for that reason, potentially stifle critical expression. Such scenarios underscore a concern about the facilitation of educators' civic writing, and whether or not it flourishes within more formal or interest-driven settings. Facilitating educator participation in open and critical civic dialogue has required careful attention to shared norms alongside respect for participants' risk-taking and transparency. If, as we believe, annotation can help inscribe educators' civic and social futures (New London Group, 1996), then the formality of learning environment is of secondary concern to the intentional cultivation of civic writing practices, like SUBLIMATES, across everyday sociopolitical texts and contexts.

\section{Conclusion}

Educators' civic writing practices analyzed in this study illustrate professional learning and deliberation that, we assert, shapes discourse within certain political and pedagogical communities. Across a corpus of OWA associated with one Marginal Syllabus conversation, we identified ten civic writing practices that encouraged a marginal space of community formation 
to blossom public civic thought and to host a bazaar of ideas that were collectively engendered and exchanged by educators. The Marginal Syllabus, as a structured but informal learning environment, demonstrated that the walls of digital text glisten with the possibilities for collective authorship and critical civic learning. Such opportunities for educator dialogue and learning are infrequent outside of formal university or professional development settings. As a civic site of hybrid expression, the Marginal Syllabus' text-turned-discursive context emphasizes the possibilities of civic writing fostered through collaborative annotation. Additional research should examine potential classroom OWA use and the role of annotation in educator expression and critical conversation. Be that as it may, this study's exploratory analysis highlights how mundane thoughts, links, and affirmations written by educators, via annotation, across digital walls are sublime instantiations of critical civic literacy.

\section{References}

Ávila, J., \& Pandya, J. (Eds.). (2013). Critical digital literacies as social practice: Intersections and challenges. New York, NY: Peter Lang.

Baker-Bell, A., Stanbrough, R., \& Everett, S. (2017). The stories they tell: Mainstream media, pedagogies of healing, and critical media literacy. English Education, 49(2), 130-152.

Barthes. R. (1977). Image music text. New York, NY: Hill \& Wang.

Beach, R. (2012). Constructing digital learning commons in the literacy classroom. Journal of Adolescent \& Adult Literacy, 55(5), 448-451.

Berners-Lee, T. (2010). Long live the Web. Scientific American, 303(6), 80-85.

Bush, V. (1945). As we may think. The Atlantic Monthly, 176(1), 101-108. 
Carnegie Corporation of New York, \& CIRCLE (2003). The civic mission of schools. New York, NY: Carnegie Corporation of New York and CIRCLE.

Chen, B. (2018). Designing for networked collaborative discourse: An UnLMS approach. TechTrends, 1-8.

Coates, T. (2015). Between the world and me. New York, NY: Random House.

Cohen, C., Kahne, J., Bowyer, B., Middaugh, E., \& Rogowski, J. (2012). Participatory politics:

New media and youth political action. Irvine, CA: DML Research Hub.

Cope, B., Kalantzis, M., \& Abrams, S. (2017). Multiliteracies: Meaning-making and learning in the era of digital text. In F. Serafini \& E. Gee (Eds.), Remixing multiliteracies: Theory and practice from New London to new times (pp. 35-49). New York, NY: Teachers College Press.

DeRosa, R., \& Jhangiani, R. (2017). Open pedagogy. In E. Mays (Ed.), A guide to making open textbooks with students (pp. 6-21). Montreal, QC: Rebus Community.

Eubanks, V. (2018). Automating inequality: How high-tech tools profile, police, and punish the poor. New York, NY: St. Martin’s Press.

Fairclough, N. (2013). Critical discourse analysis: The critical study of language. Abingdon, UK: Routledge.

Freire, P., \& Macedo, D. (1987). Literacy: Reading the word \& the world. South Hadley, MA: Bergin \& Garvey Publishers.

Garcia, A., \& Mirra, N. (in review). Writing toward justice: Designing civic literacy practices for expansive youth engagement. 
Garcia, A., Mirra, N., Morrell, E., Martinez, A., \& Scorza, D. A. (2015). The council of youth research: Critical literacy and civic agency in the digital age. Reading \& Writing Quarterly, 31(2), 151-167.

Gee, J. (2011). How to do discourse analysis: A toolkit. New York, NY: Routledge.

Gee, J. (2014). An introduction to discourse analysis: Theory and method (4th ed.). New York, NY: Routledge.

Gutiérrez, K. (2008). Developing sociocultural literacy in the third space. Reading Research Quarterly, 43(2), 148-164.

Gutiérrez, K., Baquedano-López, P., \& Tejeda, C. (1999). Rethinking diversity: Hybridity and hybrid language practices in the third space. Mind, culture, and activity, 6(4), 286-303.

Gutiérrez, K., \& Jurow, A. S. (2016). Social design experiments: Toward equity by design. Journal of the Learning Sciences, 25(4), 565-598.

Gutiérrez, K., \& Vossoughi, S. (2010). Lifting off the ground to return anew: Mediated praxis, transformative learning, and social design experiments. Journal of Teacher Education, 61(1-2), 100-117.

Hodgin, E. (2016). Educating youth for online civic and political dialogue: A conceptual framework for the digital age. Journal of Digital and Media Literacy, 4(1-2).

Jenkins, H. (2006). Convergence culture: Where old and new media collide. New York, NY: NYU Press.

Jenkins, H., Ito, M., \& boyd, d. (2015). Participatory culture in a networked era. Cambridge, UK: Polity.

Kahne, J., \& Middaugh, E. (2008). Democracy for some: The civic opportunity gap in high school (Circle Working Paper No. 59). College Park, MD: CIRCLE. 
Kalir, J. (2018). Equity-oriented design in open education. International Journal of Information and Learning Technology, 35(5), 357-367.

Kalir, J., \& Dillon, J. (in press). Educators discussing ethics, equity, and literacy through collaborative annotation. In K. Hawley (Ed.), Ethical dimensions of teaching digital literacy. Lanham, MD: Rowman \& Littlefield.

Kalir, J., \& Perez, F. (2019). The Marginal Syllabus: Educator learning and web annotation across sociopolitical texts and contexts. In A. Reid (Ed.), Marginalia in modern learning contexts (pp. 17-58). Hershey, PA: IGI Global.

Kozan, K., \& Richardson, J. C. (2014). Interrelationships between and among social, teaching, and cognitive presence. The Internet and higher education, 21, 68-73.

Ladson-Billings, G. (2006). From the achievement gap to the education debt: Understanding achievement in U.S. schools. Educational Researcher, 35(7), 3-12.

Lankshear, C., \& Knobel, M. (2011). New literacies: Everyday practices and classroom learning. Maidenhead, UK: Open University Press.

Levinson, M. (2007). The civic achievement gap. College Park, MD: CIRCLE.

Levy, R. (2011). Young children, digital technology, and interacting with text. In M. Thomas (Ed.), Deconstructing digital natives: Young people, technology and the new literacies (pp. 151-166). New York, NY: Routledge.

Lizárraga, J., \& Gutiérrez, K. (2018). Centering Nepantla literacies from the borderlands: Leveraging "in-betweenness" toward learning in the everyday. Theory into Practice, $57(1), 38-47$.

Luke, A. (2012). Critical literacy: Foundational notes. Theory into Practice, 51(1), 4-11. 
Marshall, C. (1997). Annotation: From paper books to the digital library. In Proceedings of the Second ACM International Conference on Digital Libraries (pp. 131-140). New York, NY: ACM Press.

Mattern, S. (2017). Code and clay, data and dirt: Five thousand years of urban media. Minneapolis, MN: University of Minnesota Press.

Mirra, N. (2018). Educating for empathy: Literacy learning and civic engagement. New York, NY: Teachers College Press.

Mirra, N., \& Garcia, A. (2017). Civic participation reimagined: Youth interrogation and innovation in the multimodal public sphere. Review of Research in Education, 41(1), $136-158$.

Mirra, N., Morrell, E., Cain, E., Scorza, D., \& Ford, A. (2013). Educating for a critical democracy: Civic participation reimagined in the Council of Youth Research. Democracy and Education, 21(1), 1-10.

Morgan, B. (2010). New literacies in the classroom: Digital capital, student identity, and third space. International Journal of Technology, Knowledge \& Society, 6(2), 221-239.

Morrell, E. (2013). Critical media pedagogies: Teaching for achievement in city schools. New York, NY: Teachers College Press.

National Humanities Center. (2007). Student Nonviolent Coordinating Committee, Statement of Purpose, 1960. National Humanities Center. Retrieved from http://nationalhumanitiescenter.org/pds/maai3/protest/text2/snccstatementofpurpose.pdf Neason, A. (2017). This Brooklyn artist is taking on the media. The Village Voice. Retrieved from https://www.villagevoice.com/2017/07/19/alexandra-bell-counternarratives-newyork-times/ 
New London Group. (1996). A pedagogy of multiliteracies: Designing social futures. Harvard Educational Review, 66, 60-92.

Noble, S. (2018). Algorithms of oppression: How search engines reinforce racism. New York, NY: New York University Press.

O’Hare, I. (2018). All this can be yours. Portland, OR: University of Hell Press.

Payne, K. (2017). Democratic teacher education in elementary classrooms: Learning about, through, and for thick democracy. The Journal of Social Studies Research, 41(2), 101115.

Phillips, S. (1999). Wallbangin': Graffiti and gangs in L.A. Chicago, IL: University of Chicago Press.

Reich, J., \& Ito, M. (2017). From good intentions to real outcomes: Equity by design in learning technologies. Irvine, CA: Digital Media and Learning Research Hub.

Ruitenberg, C. (2009). Educating political adversaries: Chantal Mouffe and radical democratic citizenship education. Studies in Philosophy and Education, 28(3), 269-281.

Saldaña, J. (2016). The coding manual for qualitative researchers (3rd ed.). London, UK: Sage. Sarahchadwickk. (2018). I'm a junior [Tweet]. Retrieved from https://witter.com/sarahchadwickk/status/967088933795454976

Schacht, P. (2015). Annotation. In MLA Commons Digital Pedagogy in the Humanities: Concepts, Models and Experiments. Retrieved October 2, 2017, from https://digitalpedagogy.mla.hcommons.org/keywords/annotation/

Serafini, F., \& Gee, E. (Eds.). (2017). Remixing multiliteracies: Theory and practice from New London to new times. New York, NY: Teachers College Press. 
Share, J. (2015). Media literacy is elementary: Teaching youth to critically read and create media (2nd ed.). New York, NY: Peter Lang.

Shelby, T. (2016). Dark ghettos: Injustice, dissent, and reform. Cambridge, MA: Harvard University Press.

Slocum, A., Hathaway, R., \& Bernstein, M. (2018). Striking signs: The diverse discourse of the 2018 West Virginia teachers' strike. English Education, 50(4), 365-374.

Taylor, A. (2014). The people's platform: Taking back power and culture in the digital age. New York, NY: Metropolitan Books.

Taylor, K., \& Hall, R. (2013). Counter-mapping the neighborhood on bicycles: Mobilizing youth to reimagine the city. Technology, Knowledge and Learning, 18(1-2), 65-93.

Teeters, L., Jurow, A. S., \& Shea, M. (2016). The challenge and promise of community codesign. In V. Svihla \& R. Reeve (Eds.), Design as Scholarship: Case Studies from the Learning Sciences (pp. 41-54). New York, NY: Routledge.

Tufekci, Z. (2017). Twitter and tear gas: The power and fragility of networked protest. New Haven, CT: Yale University Press.

Udell, J. (2017, January 17). A Hypothesis-powered toolkit for fact checkers. Retrieved from https://Hypothesis/blog/a-hypothesis-powered-toolkit-for-fact-checkers/

Watts, R., \& Flanagan, C. (2007). Pushing the envelope on civic engagement: A developmental and liberation psychology perspective. Journal of Community Psychology, 35, 779-792.

Whaley, D. (2017, February 24). Annotation is a now a web standard. Retrieved from https://Hypothesis/blog/annotation-is-now-a-web-standard/ 